\title{
Evaluating the potential for respiratory metagenomics to improve treatment of secondary infection and detection of nosocomial transmission on expanded COVID-19 intensive care units
}

\author{
Themoula Charalampous $^{1+}$ (1) , Adela Alcolea-Medina ${ }^{1,2+}$, Luke B. Snell ${ }^{1,3+}$, Tom G. S. Williams ${ }^{3}$, Rahul Batra ${ }^{1,3}$, \\ Christopher Alder ${ }^{1,3}$, Andrea Telatin ${ }^{4}$, Luigi Camporota ${ }^{5}$, Christopher I. S. Meadows ${ }^{5}$, Duncan Wyncoll ${ }^{5}$, \\ Nicholas A. Barrett ${ }^{5}$, Carolyn J. Hemsley ${ }^{3}$, Lisa Bryan², William Newsholme², Sara E. Boyd ${ }^{3}$, Anna Green 6 , \\ Ula Mahadeva ${ }^{6}$, Amita Patel ${ }^{1,3}$, Penelope R. Cliff ${ }^{2}$, Andrew J. Page ${ }^{4}$, Justin O'Grady ${ }^{4^{*}}$ and \\ Jonathan D. Edgeworth ${ }^{1,2,3^{*}}$
}

\begin{abstract}
Background: Clinical metagenomics $(\mathrm{CMg})$ has the potential to be translated from a research tool into routine service to improve antimicrobial treatment and infection control decisions. The SARS-CoV-2 pandemic provides added impetus to realise these benefits, given the increased risk of secondary infection and nosocomial transmission of multi-drug-resistant (MDR) pathogens linked with the expansion of critical care capacity.

Methods: CMg using nanopore sequencing was evaluated in a proof-of-concept study on 43 respiratory samples from 34 intubated patients across seven intensive care units (ICUs) over a 9-week period during the first COVID-19 pandemic wave.

Results: An 8-h CMg workflow was 92\% sensitive (95\% Cl, 75-99\%) and 82\% specific (95\% Cl, 57-96\%) for bacterial identification based on culture-positive and culture-negative samples, respectively. CMg sequencing reported the presence or absence of $\beta$-lactam-resistant genes carried by Enterobacterales that would modify the initial guidelinerecommended antibiotics in every case. CMg was also 100\% concordant with quantitative PCR for detecting Aspergillus fumigatus from 4 positive and 39 negative samples. Molecular typing using 24-h sequencing data identified an MDR-K. pneumoniae ST307 outbreak involving 4 patients and an MDR-C. striatum outbreak involving 14 patients across three ICUs.
\end{abstract}

\footnotetext{
* Correspondence: justin.ogrady@uea.ac.uk; jonathan.edgeworth@gstt.nhs.uk

${ }^{\dagger}$ Themoula Charalampous, Adela Alcolea-Medina and Luke B. Snell contributed equally to this work.

${ }^{4}$ Quadram Institute Bioscience, Norwich Research Park, Norwich, UK

${ }^{1}$ Centre for Clinical Infection and Diagnostics Research, Department of

Infectious Diseases, School of Immunology and Microbial Sciences, Kings

College London, London, UK

Full list of author information is available at the end of the article
}

C C The Author(s). 2021 Open Access This article is licensed under a Creative Commons Attribution 4.0 International License, which permits use, sharing, adaptation, distribution and reproduction in any medium or format, as long as you give appropriate credit to the original author(s) and the source, provide a link to the Creative Commons licence, and indicate if changes were made. The images or other third party material in this article are included in the article's Creative Commons licence, unless indicated otherwise in a credit line to the material. If material is not included in the article's Creative Commons licence and your intended use is not permitted by statutory regulation or exceeds the permitted use, you will need to obtain permission directly from the copyright holder. To view a copy of this licence, visit http://creativecommons.org/licenses/by/4.0/. The Creative Commons Public Domain Dedication waiver (http://creativecommons.org/publicdomain/zero/1.0/) applies to the data made available in this article, unless otherwise stated in a credit line to the data. 
Conclusion: $\mathrm{CMg}$ testing provides accurate pathogen detection and antibiotic resistance prediction in a same-day laboratory workflow, with assembled genomes available the next day for genomic surveillance. The provision of this technology in a service setting could fundamentally change the multi-disciplinary team approach to managing ICU infections. The potential to improve the initial targeted treatment and rapidly detect unsuspected outbreaks of MDR-pathogens justifies further expedited clinical assessment of CMg.

\section{Background}

The intensive care unit (ICU) is a dynamic environment with frequent staff-patient contact for invasive monitoring, interventions and personal care that together introduce the risk of secondary or nosocomial infection [1]. Invasive ventilation can introduce organisms into the lungs causing ventilator-acquired pneumonia (VAP) which carries high attributable mortality and drives up to $70 \%$ of antimicrobial prescribing [2]. Patients with suspected VAP receive guideline-directed empiric antibiotics until culture results return, typically $2-4$ days later [3]. Invasive pulmonary aspergillosis (IPA) is also increasingly recognised on ICU particularly with severe influenza [4] and after host immunosuppression, but culture lacks sensitivity and biomarker tests have low specificity and long turnaround times whilst gold standard histopathology is rarely used [5].

SARS-CoV-2 has put considerable strain on ICUs, due to the expansion of bed capacity with severely unwell patients, which has the potential to increase nosocomial infection, antimicrobial treatment and antimicrobial resistance (AMR). A high prevalence of Gram-negative bacteria (GNB) particularly Klebsiella spp. has been reported [6], and there are reports of secondary IPA [7]. COVID-19 patients also receive steroid therapy, which could exacerbate bacterial or fungal infections [8]. The COVID-19 pandemic therefore re-enforces the need for rapid comprehensive diagnostics to improve antimicrobial stewardship and help prevent emergence and transmission of multi-drug-resistant (MDR) organisms.

Clinical metagenomics $(\mathrm{CMg})$ using nanopore sequencing has the potential to meet these needs due to its unbiased pan-microbial coverage and ability to provide real-time analysis [9]. CMg has been evaluated for respiratory, urinary tract and prosthetic joint infections [9-12]; however, its ability to simultaneously provide rapid results informing antimicrobial treatment and infection control decisions has only been demonstrated in a few studies [13]. We therefore performed a proof-ofconcept study using a saponin-based, previously published $\mathrm{CMg}$ pipeline [9] with a slight modification-depletion reaction was performed at $37{ }^{\circ} \mathrm{C}$ instead of room temperature (workflow outlined in Fig. 1). CMg was used on respiratory specimens from COVID-19 patients with suspected secondary bacterial or fungal pneumonia. The objective was to assess whether rapid CMg testing had the potential to inform initial antimicrobial treatment decisions and rapidly detect outbreaks in an expanded COVID-19 intensive care setting.

\section{Methods}

\section{Clinical setting and data collection}

Clinical, microbiological and ward location data were collected by the primary care team from all intubated patients with a documented SARS-CoV-2 RTPCR positive test admitted to the 3 pre-existing ICUs with expanded capacity and 4 newly opened COVID-19 ICUs at St Thomas' Hospital, London. All healthcare staff used additional personal protective equipment (PPE) according to Public Health England (PHE) guidelines. Updated ICU empiric antimicrobial guidelines recommended 3 days co-amoxiclav for COVID-19 patients on admission, piperacillin-tazobactam for first suspected ICU-acquired respiratory infection and meropenem for subsequent infections or where resistance was suspected.

\section{Sample selection and analysis}

Between 11 April and 15 June 2020, surplus clinical respiratory samples from 34 ICU COVID-19 patients with suspected secondary infections were processed by the research team after routine processing. Samples processed by the clinical laboratory included respiratory clinical samples (tracheal aspirates, bronchoalveolar lavages (BALs) and non-direct bronchoalveolar lavages (NDLs, a BAL collected without the use of a bronchoscope) for (i) routine microbiological culture for bacterial and fungal pathogens or detection of SARS-CoV-2 by PCR and (ii) sera and BALs for galactomannan (GM) antigen detection when Aspergillus infection was suspected (described further below). Surplus of samples subjected to routine microbiology culture for bacterial and fungal pathogens was only collected by the research team for $\mathrm{CMg}$ processing after routine testing was performed. In total, 43 surplus samples were collected which included 10 BALs, 6 tracheal aspirates and 27 NDLs. These were used to assess the performance of the CMg workflow which included rapid bacterial and fungal identification, AMR gene detection and pathogen genomic epidemiology (Fig. 1). Samples were anonymised prior to submission to the research team. The clinical care team collected relevant clinical and laboratory data to create an anonymised dataset given to the research team who had no 


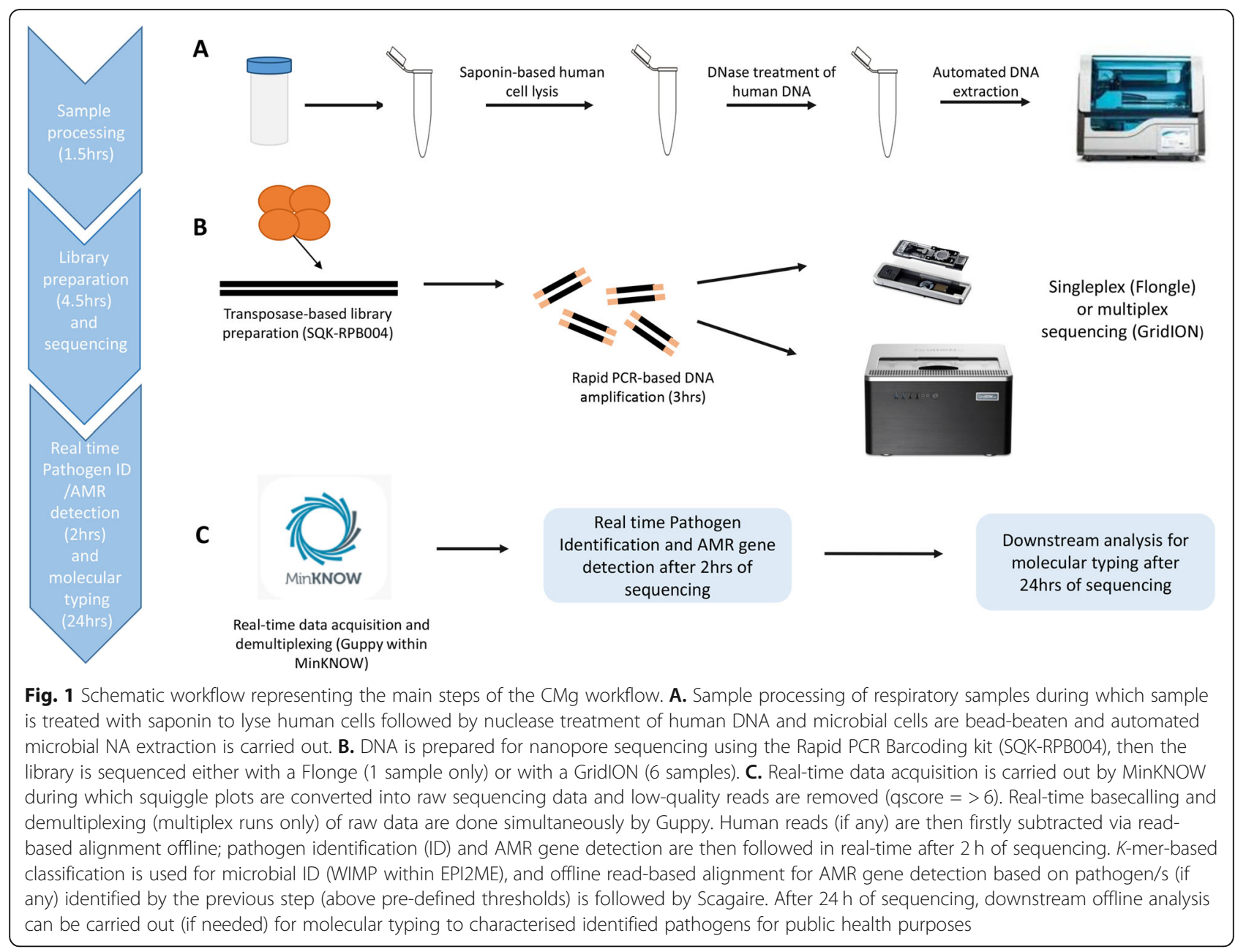

access to patient identifiable data at any time. The intensive care clinical team was not aware of the $\mathrm{CMg}$ results whilst caring for the patients. Collected samples were stored (1-4 days) at $4{ }^{\circ} \mathrm{C}$ until processed aseptically. The full process for sample collection, nanopore sequencing, data linkage and anonymization was approved by a research ethical committee (North West Preston REC: reference 18/NW/0584).

\section{Routine microbiological processes}

Routine processing of respiratory samples was initially performed in an ISO15189-accredited laboratory according to standard operating procedures [14]. Briefly, BALs and NDLs were centrifuged at $1200 \mathrm{~g}$ for $10 \mathrm{~min}$, and the supernatant was discarded leaving $500 \mu \mathrm{l}$ residual volume. The remaining sample was resuspended (vortex for $10 \mathrm{~s}$ ), and $10 \mu \mathrm{l}$ of sample was streaked onto blood agar, chocolate agar and fastidious anaerobic agar (FAA). Tracheal aspirates were not centrifuged and were directly streaked onto blood agar and chocolate agar plates. All plates were then incubated at $37{ }^{\circ} \mathrm{C}$ in an aerobic and an anaerobic environment for $48 \mathrm{~h}$. Sabouraud agar plates were set up for the detection of Candida spp. and Aspergillus spp. and incubated for 5 days at $37^{\circ} \mathrm{C}$ in aerobic conditions. Bacterial colonies were identified using MALDI-TOF (Bruker) except the Aspergillus spp. where microscopy was performed. Culture-negative samples were reported as 'normal respiratory flora (NRF)' or as 'no growth (NG)' when no organisms would be observed after $48 \mathrm{~h}$ of incubation.

Antibiotic susceptibility by agar diffusion was performed for any reported grown pathogens, following guidelines of the European Committee on Antimicrobial Susceptibility Testing (EUCAST) methodology [15].

\section{Reporting of respiratory pathogens from $\mathrm{CMg}$ data}

Microorganisms referred to as 'respiratory pathogens' or 'pathogens' in this study were defined as common agents causing respiratory infection in ICU patients. A predefined pathogen list was compiled based on previous lower respiratory tract infections studies [9, 16-18] (listed in Additional file 1: Table S1). Respiratory pathogens identified in samples tested in this study were Acinetobacter baumanni, Aspergillus fumigatus, Bulkhoderia 
spp., Citrobacter koseri, Citrobacter freundii, Enterobacter cloacae complex, Klebsiella aerogenes, Klebsiella oxytoca, Klebsiella pneumoniae, Morganella morganii, Proteus mirabilis, Pseudomonas aeruginosa, Serratia marcescens, Stenotrophomonas maltophilia and Staphylococcus aureus. Haemophilus influenzae was identified in one negative process control only. Corynebacterium striatum was not considered a pathogen but was only investigated in our study for molecular typing due to the increased number of incidence of the organism in ICU during the study. Microorganisms identified in this study (above chosen thresholds) but not defined as respiratory pathogens are listed in Additional file 1: Table S2.

\section{Routine SARS-CoV-2 RT-PCR}

For routine detection of SARS-CoV-2, reversetranscriptase (RT) PCR was performed by the clinical laboratory using the Highplex 24 system (AusDiaganostics Pty Ltd.), according to the manufacturer's instructions (SARS-CoV-2, Influenza and RSV 8-well, Catalogue number: 20081, version: 08), which targets the Orf1ab and Orf8 of SARS-CoV-2 and requires $200 \mu \mathrm{l}$ of respiratory clinical samples.

\section{Galactomannan assay}

For GM antigen detection, the clinical laboratory sent referred samples to the Mycology Reference Laboratory National Infection Services, PHE at Southmead Hospital, Bristol. The Platelia Aspergillus Antigen kit (BIO-RAD 62794) was used according to the manufacturer's instructions to detect GM in the sera and BALs only. The assay is a one-stage immunoenzymatic sandwich microplate and uses rat EBA-2 monoclonal antibodies designed to detect Aspergillus GM antigens in clinical samples.

\section{A. fumigatus qPCR assay}

A probe-based qPCR assay was performed on all samples from the CMg cohort $(n=43)$ to detect $A$. fumigatus DNA (previously described in [19]). The assay was done using the QuantStudio 7 Flex (Applied Biosystems). The master mix for each reaction consisted of $10 \mu \mathrm{l}$ of LightCycler 480 probe master $(2 \times), 0.4 \mu \mathrm{l}$ of probe (final concentration $0.2 \mu \mathrm{M}$ ) and $0.5 \mu \mathrm{l}$ each of the forward and reverse primer (final concentration $0.25 \mu \mathrm{M}) ; 2 \mu \mathrm{l}$ of DNA was added, and nuclease-free water was added to the reaction to make the volume up to $20 \mu \mathrm{l}$. The $\mathrm{qPCR}$ conditions were pre-incubation at $95^{\circ} \mathrm{C}$ for $15 \mathrm{~min}$ and amplification for 40 cycles at $94{ }^{\circ} \mathrm{C}$ for $15 \mathrm{~s}$ and $60^{\circ} \mathrm{C}$ for $1 \mathrm{~min}$.

\section{Nanopore metagenomic sequencing}

Host DNA depletion, microbial DNA extraction and sequencing were performed based on previously published methods [9]. Briefly, collected surplus respiratory samples were sputasol-treated (SR0233 - Oxoid) in a 1:1 ratio for $15 \mathrm{~min}$ at $37^{\circ} \mathrm{C}$ to liquefy samples before treatment with working stock of $1 \%$ saponin $\left(15 \mathrm{~min}\right.$ at $37^{\circ} \mathrm{C}$ shaking at 1000 rpm; Sigma - 47036-50G-F) to induce host cell lysis and release of host DNA that was digested with HL-SAN DNase $\left(15 \mathrm{~min}\right.$ at $37^{\circ} \mathrm{C}$ shaking at $1000 \mathrm{rpm}$; Articzymes - 70910-202). Samples were then washed twice in $1.5 \mu \mathrm{l}$ PBS and centrifuged to pellet bacterial and fungal organisms. The pellet was re-suspended in lysis buffer $(600 \mu \mathrm{l}$; Qiagen UK) for bead-beating (Lysis Matrix E beads and 1 min at $50 \mathrm{o} / \mathrm{s}$ on FastPrep 24; MP Biomedical) to release microbial DNA followed by centrifugation (1 min at top speed in benchtop centrifuge) and removal of $\sim 200 \mu \mathrm{l}$ supernatant. The supernatant was then proteinase $\mathrm{K}$ treated (5 min at $65^{\circ} \mathrm{C}$ shaking at $1000 \mathrm{rpm}$; Qiagen) to digest residual proteins. Finally, samples were incubated at $95^{\circ} \mathrm{C}$ for $30 \mathrm{~min}$ to kill residual organisms before DNA extraction using the Fast Pathogen 200 protocol on a MagNA Pure 24 System (Roche UK). DNA was quantified using the high sensitivity dsDNA assay kit (Thermo Fisher) on the Qubit 3.0 Fluorometer (Thermo Fisher). Fragment size and quality of metagenomic libraries were analysed using the TapeStation 4200 (Agilent Technologies) automated electrophoresis platform.

Samples were batched for CMg sequencing (6 samples per run) plus a negative process control. In the negative process control, sample was replaced with water and processed through the full pipeline including human DNA depletion, DNA extraction library preparation, sequencing and analysis. This control was introduced to monitor barcode cross-talk and laboratory and/or reagent contamination. Library preparation was performed using the Rapid PCR Barcoding Kit (ONT) as previously described [9] but with a 6-min PCR extension time. Library was loaded onto nanopore flow cells (R9.4.1) with sequencing performed on the GridION platform. The ONT MinKNOW software (version 3.6.5) acquired raw sequence data with live basecalling by ONT Guppy (version 3.2.10). Sequencing was run for $24 \mathrm{~h}$ with the first $2 \mathrm{~h}$ data used for pathogen identification by WIMP analysis. Human reads were discarded by alignment with genome reference (GCA_000001405.15, assembly GRCh38.p13 version) and non-human reads were exported and used for pathogen identification and AMR gene detection as previously described [20] (see Fig. 1 for a schematic workflow of the CMg method).

\section{Pathogen identification and resistance gene prediction}

The EPI2ME Antimicrobial Resistance pipeline (ONT, version v2020.2.10-3247478) was used for bacterial and fungal pathogen identification as previously described [9]. The EPI2ME Antimicrobial Resistance pipeline uses What's In My Pot (WIMP), for the identification of respiratory bacterial and fungal pathogens. WIMP (v3.4.0) 
uses 'Centrifuge' a $k$-mer-based metagenomic classifier [20] and a pre-built database containing 56,044 sequences, which is based on the NCBI taxonomy and RefSeq database [21] but is further curated by ONT to remove low-complexity sequence regions (protocol available at https://figshare.com/articles/online_resource/Additional_ file_3/16722829/1) [22].

Potential bacterial pathogen(s) were reported if they represented $\geq 1 \%$ of total microbial reads with a centrifuge score $\geq 2504$ as a quality threshold. Aspergillus spp. were only reported if $\geq 10$ reads (with a centrifuge score $\geq 2504$ ) were identified. To remove barcode cross-talk between samples on the multiplexed runs, $0.1 \%$ of pathogen reads were removed from all samples (i.e. from each barcode) if there were $>10,000$ cumulative pathogen reads identified from the 6 samples on the flow cell. Any pathogens identified in the negative control (with > 5 classified reads) after application of all thresholds were considered contaminants, and these pathogens were removed from all multiplexed samples on the sequencing run.

Thresholds used in this study for pathogen identification were defined using the dataset published by Charalampous et al. [9] as the training set (see Additional file 1: Supplementary methods).

Sensitivity and specificity were calculated on a persample basis [14] using the Clopper-Pearson exact method (https://www.medcalc.org/calc/diagnostic_test.php).

Resistance genes were detected from $2 \mathrm{~h}$ of sequencing using Scagaire with default parameters. Scagaire utilises a bundled database containing the 40 most commonsequenced bacterial species in the RefSeq database and only reports clinically relevant resistance genes [23]. Briefly, FASTQ files were converted into FASTA files and then analysed using Abricate [24], with default parameters, to detect resistance genes against the ResFinder database. Then, Scagaire was used to predict and filter out clinically relevant genes based on the pathogen identified by metagenomics and the Abricate output file. Clinically relevant gene alignments with $<90 \%$ coverage were removed and only resistance genes with $>1$ gene alignment were reported to remove any possible bioinformatics errors.

This analysis was only carried out to determine the presence or absence of genotypic determinants conferring resistance to antibiotics used on the ICU for GNB and Staphylococcus aureus. Furthermore, analysis was only performed where there was concordance between organisms identified in both routine culture and $\mathrm{CMg}$, so that genotypic-determinants and culture results could be directly compared. Samples where Pseudomonas aeruginosa was identified as the sole pathogen were excluded, due to known difficulty in predicting phenotypic resistance based on genotypic elements only [25, 26].

\section{DNA extraction and nanopore sequencing of $K$.} pneumoniae BSI isolates

Isolates of $K$. pneumoniae, previously identified by MALDI-TOF, were subcultured on blood agar and incubated for $48 \mathrm{~h}$ at $35{ }^{\circ} \mathrm{C}$ aerobically. For bacterial DNA extraction, 4-5 colonies were selected and were mixed in $500 \mu \mathrm{l}$ of PBS. The mixed solution was transferred into Lysing Beads - Matrix E (MP Biomedicals 116005500 ) and bead-beaten for $4 \mathrm{~m} / \mathrm{s}$ for $40 \mathrm{~s}$ seconds using a MP Biomedicals FastPrep-24 5G Instrument (MP Biomedicals - 116005500). The sample was then centrifuged for $1 \mathrm{~min}$ at $12,000 \mathrm{rpm}$, and $100 \mu \mathrm{l}$ of the supernatant was collected and transferred to a clean 1.5-ml Eppendorf tube. Then, extracted DNA was then subjected to a bead wash to remove short DNA fragments. Briefly, $0.5 \times$ of Agencourt AMPure XP beads (Beckman Coulter-A63881) was added, mixed and incubated for $10 \mathrm{~min}$ at RT. The tube was placed in a magnetic rack and washed twice with $80 \%$ of ethanol before the sample was eluted in $50 \mu$ of nuclease-free water.

Next, library preparation for nanopore sequencing was done, using the native barcoding genomic DNA (ONT EXP-NBD114 and SQK-LSK109 kits). Isolates were sequenced on a GridION for $48 \mathrm{~h}$, following the manufacturer's instructions.

\section{Klebsiella spp. and C. striatum SNP analysis}

Representative complete reference genomes for each species were downloaded from RefSeq to generate consensus sequences [27]. K. pneumoniae reads from 7 patients (8 samples) were aligned to the K. pneumoniae subsp. pneumoniae HS11286 strain. K. aerogenes reads from 4 samples (3 patients) were aligned to the $K$. aerogenes strain NCTC9735. C. striatum reads in 5 samples (4 patients) were aligned to C. striatum strain $\mathrm{KC}-\mathrm{Na}-01$. Reads were aligned to each matching reference genome using minimap2 (v 2.17-r941) [28]. A consensus sequence was generated using bcftools ( $\mathrm{v}$ 1.10.2) [29]. SNP-sites (v2.5.1) [30] was used to identify SNPs between each sample, and SNP distances were calculated using SNP-dists (v0.7.0) (https://github. com/tseemann/snp-dists). Multi-locus sequence typing was performed using mlst (v2.19.0) [31]. FASTQ/ FASTA files were transformed using PyFASTAQ (v3.17.0) (https://github.com/sanger-pathogens/ Fastaq). SNP distances were calculated using SNP-dists (v0.7.0) (https://github.com/tseemann/snp-dists). Genomes with a genetic similarity of $\geq 99.99 \%$ were considered related, and plausible outbreaks were investigated using traditional epidemiological methods. The threshold for genetic similarity was based on previous studies [32, 33] and the latest nanopore accuracy data (https:// nanoporetech.com/accuracy). 


\section{Results}

Clinical and microbiological characteristics of COVID-19 patients

In total, 175 invasively ventilated COVID-19 patients were admitted to 7 ICUs, between 11 April and 15 June 2020 , of which 34 patients with suspected secondary infection were chosen for inclusion in this CMg proof-ofconcept study and had one or more respiratory samples analysed by CMg (Table 1). Admission characteristics of the $\mathrm{CMg}$ group were broadly comparable to those not receiving $\mathrm{CMg}$ testing, with a median age of 52 and $70 \%$ being male, although they had a longer median length of hospital-stay (32 days [IQR 24-47] compared to 25 days [IQR 15-45] in the non-CMg group). The $34 \mathrm{CMg}$ patients had 156 respiratory samples collected with organisms identified by routine cultures from at least one sample. The main respiratory sample Gram-negative bacteria were Klebsiella spp. (53\%), Citrobacter spp. (15\%) and E. coli (9\%). The main Gram-positive bacteria were S. aureus (9\%), C. striatum (24\%) and Enterococcus spp. (12\%). C. albicans, other Candida spp. and Aspergillus spp. were cultured from 38\%, 15\% and 9\% of patients, respectively. Respiratory pathogens cultured from $\mathrm{CMg}$ patients were representative of those found in the samples from the patient cohort over the 9-week period of the CMg study (Table 1) as well as with patients admitted across the 7 ICUs during the first wave from March to June 2020 (Additional file 1: Table S3).

\section{Performance of CMg compared with routine culture for pathogen detection}

Potential respiratory pathogens were cultured from 26/ 43 (60\%) samples (18 NDLs, 4 BALs and 4 tracheal aspirates) tested by CMg (Fig. 1) with 17 samples (9 NDLs, 6 BALs and 2 tracheal aspirates) reported by culture either as no growth or not containing any pathogenic organisms (Table 2). CMg identified 24/26 culturereported pathogens (92\% sensitive; 95\% CI, 75-99\%) using pre-defined criteria (i.e. $\geq 1 \%$ of microbial classified reads with a centrifuge score $\geq 2504$ ) (Table 2). Metagenomics did not report $K$. aerogenes in two polymicrobial samples (S44 and S45) where scanty growth of $K$. aerogenes was reported by culture (S45 was also culture-positive for $C$. striatum). $K$. aerogenes reads were identified in both samples by CMg sequencing but were below pre-defined thresholds (Additional file 1: Table S4A). Applying the barcode cross-talk threshold did not affect pathogen identification in samples but allowed identification of contaminants in negative controls- $E$. coli was the most common contaminant identified in 8/ 11 negative controls (Additional file 1: Table S4B).

$\mathrm{CMg}$ identified 6 additional pathogens in 6 culturepositive samples (3 Klebsiella spp., 1 S. aureus, 1 C. koseri and 1. C. freundii) (Table 2). Three of these organisms were identified by culture in other respiratory samples from those patients (K. oxytoca (S8), K. pneumoniae (S37) and $C$. koseri (S61)). CMg also reported 3 additional pathogens in 3/17 culture-negative samples (one $A$. fumigatus (S55) and two S. aureus (S16 and S41)). The A. fumigatus was from a patient that had positive serum GM and culture-positive $A$. fumigatus respiratory samples that were not tested in this study (Table 4) resulting in a specificity of $82 \%$ (95\% CI, 57-96\%) based on culture-negative samples only. Considering additional species identified by CMg only ( $n=9 / 43$ samples) as 'false-positive findings', specificity was 79\% (95\% CI, 64-90\%). Note that specificity and sensitivity were calculated on a per-sample basis; hence, culture-positive samples with additional pathogens reported by CMg only were not considered as falsepositives and only culture-positive samples where all culture-reported pathogens in the sample were also detected by $\mathrm{CMg}$ were considered true-positives (sample numbers were too small to analyse on a per-pathogen basis).

\section{Impact of resistance gene detection on guideline-directed empiric beta-lactam antibiotic selection}

Two-hour CMg sequencing data was analysed from 20 of 26 culture-positive samples where the presence of resistance genes could predict phenotypic resistance and impact on guideline-directed beta-lactam treatment (Table 3). This analysis included (i) samples positive for Enterobacterales or Acinetobacter spp. where the presence of beta-lactam resistance could change advice on first-line beta-lactam treatment and (ii) presence of $m e c A$ genes in $S$. aureus culture-positive samples. The remaining 6 culture-positive samples were not positive for Enterobacterales and were not included in this analysis.

There was concordance between genotypic $\mathrm{CMg}$, and the reported phenotypic beta-lactam resistance in all but one sample. Extended-spectrum $\beta$-lactamase (ESBL) genes were detected in 4 samples containing $K$. pneumoniae that was phenotypically reported as an ESBL (Table 3). These included ESBL bla $a_{\mathrm{TEM}}$ genes identified in samples S49, S59 and S31. Additionally, bla $a_{\mathrm{SHV}}$ and bla $a_{\mathrm{CTX}-\mathrm{M}}$ genes were identified in S31 and S59. In S63, culture reported a co-amoxiclav- and piperacillin-tazobactam-resistant $K$. pneumoniae, and a bla $a_{\mathrm{SHV}}$ gene was identified by $\mathrm{CMg}$ possibly explaining the reported phenotype.

No $\beta$-lactam resistance genes were found in 8 samples containing 9 susceptible Enterobacterales (Additional file 1: Table S5), but $b l a_{\mathrm{TEM}}$ and $b l a_{\mathrm{SHV}}$ genes were detected in a sample with $K$. pneumoniae having no reported phenotypic resistance (S34). Resistance phenotypes could not be genotypically predicted in two samples with light bacterial growth of A. baumanni (S35) and K. aerogenes (S62) due to low read count by metagenomic 
Table 1 Clinical characteristics and results of routine microbiological tests performed on intubated COVID-19 patients during the CMg study across 7 linked dedicated COVID-19 intensive care units on Guy's and St Thomas' Hospital sites

\begin{tabular}{lll}
\hline & Non-metagenomics group $(\boldsymbol{n}=\mathbf{1 4 1})$ & Metagenomics group $^{\mathbf{a}}(\boldsymbol{n}=\mathbf{3 4})$ \\
\hline Median age (IQR) & $56(46-61)$ & $52(41-58)$ \\
Sex-male & $101(72 \%)$ & $23(70 \%)$ \\
Ethnicity & & \\
$\quad$ White & $49(35 \%)$ & $16(47 \%)$ \\
$\quad$ Black and minority ethnicities & $74(52 \%)$ & $15(44 \%)$ \\
$\quad 19(13 \%)$ & $3(9 \%)$ \\
Mort known & $34(25 \%)$ & $8(24 \%)$ \\
Length of stay (IQR) & 25 days (15-45) & 32 days $(24-47)$ \\
Respiratory cultures in ICU & \\
Median samples per patient (IQR) & & $4(4-6)$ \\
Total number of samples/patients tested & $2(1-3)$ & $180 / 34$
\end{tabular}

Organisms from respiratory culture whilst in ICU (number of individuals who ever had the following organisms in any sample)

$\begin{array}{lll}\text { Klebsiella spp. } & 48(34 \%) & 18(53 \%) \\ \text { Staphylococcus aureus } & 14(10 \%) & 3(9 \%) \\ \text { Citrobacter spp. } & 14(10 \%) & 5(15 \%) \\ \text { Escherichia coli } & 7(5 \%) & 3(9 \%) \\ \text { Pseudomonas spp. } & 10(7 \%) & 1(3 \%) \\ \text { Corynebacterium striatum } & 8(6 \%) & 8(24 \%) \\ \text { Enterococcus spp. } & 12(9 \%) & 4(12 \%) \\ \text { Serratia spp. } & 9(6 \%) & 2(6 \%) \\ \text { Enterobacter spp. } & 6(4 \%) & 1(3 \%) \\ \text { Haemophilus spp. } & 2(1 \%) & 0(0 \%) \\ \text { Stenotrophomonas maltophilia } & 1(3 \%) \\ \text { Proteus spp. } & 4(3 \%) & 4(12 \%) \\ \text { Morganella spp. } & 0(0 \%) & 1(3 \%) \\ \text { Acinetobacter spp. } & 0(0 \%) & 1(3 \%) \\ \text { Streptococcus pyogenes } & 0(0 \%) & 0(0 \%) \\ \text { Candida albicans } & 3(2 \%) & 13(38 \%) \\ \text { Candida spp. (non-albicans) } & 40(28 \%) & 5(15 \%) \\ \text { Aspergillus spp. } & 10(7 \%) & 3(9 \%) \\ \text { No organisms isolated } & 1(1 \%) & 2(6 \%)\end{array}$

Galactomannans (GMs)

Bronchoalveolar lavage (BAL) GMs

Number of tests/patients tested

Positive tests/patients positive

$0 / 0$

\section{Serum GMs}

Number of tests/patients tested

${ }^{a}$ One patient was SARS-CoV-2 RNA PCR-negative but had clinical diagnosis of COVID-19

${ }^{b}$ One patient in the metagenomics group and 48 patients from the non-metagenomics group had no respiratory specimens collected whilst on ICU during the study period 
Table 2 Comparison of pathogens reported by routine culture with metagenomics sequencing in respiratory samples

\begin{tabular}{|c|c|c|c|c|c|}
\hline Patient ID & Sample ID & $\begin{array}{l}\text { Semi-quantitative } \\
\text { routine culture report }^{\text {a }}\end{array}$ & $\begin{array}{l}\text { Pathogens identified by } \\
\text { metagenomic sequencing }\end{array}$ & $\begin{array}{l}\text { Pathogen reads }{ }^{\mathrm{b}} \text { identified by } \\
\text { metagenomic sequencing }\end{array}$ & $\begin{array}{l}\text { Microbial reads }{ }^{\mathbf{b}} \text { identified by } \\
\text { metagenomic sequencing }\end{array}$ \\
\hline 26 & S35 & Acinetobacter spp. (L) & A. baumannii & 99 & 853 \\
\hline 100 & S39 & C.koseri $(\mathrm{H})$ & $\begin{array}{l}\text { C. koseri } \\
\text { K. pneumoniae }\end{array}$ & $\begin{array}{l}23,870 \\
284\end{array}$ & 26,251 \\
\hline 121 & S37 & $\begin{array}{l}\text { P.mirabilis (M) } \\
\text { M.morganii (M) }\end{array}$ & $\begin{array}{l}\text { P. mirabilis } \\
\text { M morgannii } \\
\text { K. pneumoniae }\end{array}$ & $\begin{array}{l}397 \\
28,300 \\
876\end{array}$ & 45,395 \\
\hline 177 & S36 & S. aureus $(\mathrm{H})$ & S. aureus & 109,767 & 119,881 \\
\hline 196 & $\$ 42$ & B. cenocepacia $(\mathrm{L})$ & Burkholderia spp. & 34,347 & 51,551 \\
\hline 400 & $\$ 49$ & K. pneumoniae (M) & K. pneumoniae & 594 & 2202 \\
\hline 408 & S20 & S. aureus (M) & S. aureus & 36,281 & 38,708 \\
\hline \multirow[t]{2}{*}{441} & S21 & E. cloacae (M) & E. cloacae & 62,314 & 75,866 \\
\hline & S51 & $\begin{array}{l}\text { S. aureus }(\mathrm{L}) \\
\text { C. koseri }(\mathrm{L})\end{array}$ & $\begin{array}{l}\text { S. aureus } \\
\text { C. koseri }\end{array}$ & $\begin{array}{l}5203 \\
2262\end{array}$ & 8582 \\
\hline 550 & S10 & K. pneumoniae (M) & K. pneumoniae & 69,029 & 75,350 \\
\hline 563 & $\mathbf{S} 28$ & Aspergillus (S) & $\begin{array}{l}\text { A. fumigatus } \\
\text { S. aureus }\end{array}$ & $\begin{array}{l}2649 \\
3165\end{array}$ & 44,684 \\
\hline 613 & S18 & Negative & Negative & 0 & 22,776 \\
\hline 618 & S45 & K. aerogenes (S) & - & 104 & 1228 \\
\hline \multirow[t]{3}{*}{677} & S52 & K. aerogenes $(\mathrm{L})$ & K. aerogenes & 5277 & 38,854 \\
\hline & S54 & Negative & Negative & 1758 & 3015 \\
\hline & 563 & K. pneumoniae (M) & K. pneumoniae & 17,034 & 147,379 \\
\hline 727 & S53 & Negative & Negative & 0 & 0 \\
\hline \multirow[t]{2}{*}{740} & S30 & Negative & Negative & 0 & 759 \\
\hline & S59 & K. pneumoniae (M) & K. pneumoniae & 99,186 & 119,458 \\
\hline \multirow[t]{2}{*}{749} & $\$ 40$ & Negative & Negative & 0 & 1157 \\
\hline & S62 & K. aerogenes $(\mathrm{L})$ & K. aerogenes & 184 & 1021 \\
\hline \multirow[t]{2}{*}{815} & S25 & Negative & Negative & 0 & 1413 \\
\hline & S46 & C. koseri (M) & C. koseri & 237 & 462 \\
\hline 855 & S41 & Negative & S. aureus & 1365 & 31,067 \\
\hline \multirow[t]{2}{*}{872} & S11 & K. pneumoniae $(\mathrm{H})$ & K. pneumoniae & 16,828 & 35,668 \\
\hline & S61 & $\begin{array}{l}\text { P. mirabilis }(\mathrm{H}) \\
\text { K. pneumoniae }(\mathrm{M})\end{array}$ & $\begin{array}{l}\text { P. mirabilis } \\
\text { K. pneumoniae } \\
\text { C. koseri }\end{array}$ & $\begin{array}{l}29,797 \\
14,118 \\
815\end{array}$ & 47,924 \\
\hline 1033 & S8 & A. fumigatus (S) & $\begin{array}{l}\text { A. fumigatus } \\
\text { K. oxytoca }\end{array}$ & $\begin{array}{l}77 \\
44\end{array}$ & 1399 \\
\hline 1036 & S5 & Negative & Negative & 0 & 0 \\
\hline 1054 & S31 & K. pneumoniae $(\mathrm{L})$ & K. pneumoniae & 28,056 & 31,800 \\
\hline \multirow[t]{2}{*}{1065} & S16 & Negative & S. aureus & 1768 & 43,692 \\
\hline & S19 & Negative & Negative & 0 & 10,371 \\
\hline 1069 & S17 & $P$. aeruginosa $(M)$ & P. aeruginosa & 1457 & 1905 \\
\hline 1082 & S14 & Negative & Negative & 0 & 205 \\
\hline 1092 & S27 & Negative & Negative & 0 & 1413 \\
\hline 1262 & S29 & Negative & Negative & 0 & 759 \\
\hline 1292 & $\$ 44$ & $\begin{array}{l}\text { S. marcescens }(L) \\
\text { K. aerogenes }(S)\end{array}$ & $\begin{array}{l}\text { S. marcescens } \\
\text { C. freundii }\end{array}$ & $\begin{array}{l}53,082 \\
6082\end{array}$ & 65,078 \\
\hline 1346 & S56 & $\begin{array}{l}\text { A. fumigatus }(S) \\
\text { P. mirabilis }(L)\end{array}$ & $\begin{array}{l}\text { A. fumigatus } \\
\text { P. mirabilis }\end{array}$ & $\begin{array}{l}79 \\
11,323\end{array}$ & 36,658 \\
\hline
\end{tabular}


Table 2 Comparison of pathogens reported by routine culture with metagenomics sequencing in respiratory samples (Continued)

\begin{tabular}{llllll}
\hline Patient ID & Sample ID & $\begin{array}{l}\text { Semi-quantitative } \\
\text { routine culture report }\end{array}$ & $\begin{array}{l}\text { Pathogens identified by } \\
\text { metagenomic sequencing }\end{array}$ & $\begin{array}{l}\text { Pathogen reads }{ }^{\mathbf{b}} \text { identified by } \\
\text { metagenomic sequencing }\end{array}$ & \begin{tabular}{l} 
Microbial reads $^{\mathbf{b}}$ identified by $^{\text {metagenomic sequencing }}$ \\
\hline 1440
\end{tabular} \\
\hline S33 & Negative & Negative & 0 & 1176 \\
1457 & S64 & Negative & Negative & 0 & 24,484 \\
& S65 & Negative & Negative & 0 & 45,990 \\
1503 & S1 & K. aerogenes (L) & K. aerogenes & 138,626 & 145,195 \\
1512 & S34 & K. pneumoniae (L) & K. pneumoniae & 38,758 & 82,796 \\
1538 & S55 & Negative & A. fumigatus & 16 & 9146
\end{tabular}

${ }^{a}$ Reported growth by culture for each pathogen. $H=$ heavy growth, $M=$ moderate growth, $L$ = light growth, $S$ scanty growth

${ }^{b}$ Criteria for reporting organisms was $\geq 1 \%$ of microbial-classified reads and with a centrifuge score $\geq 2504$ and $>9$ reads for $A$. fumigatus only

sequencing. No carbapenemases were detected in any sample, and no $\mathrm{SCC}_{\text {mec }}$ elements were found in the two samples growing $S$. aureus, consistent with the reported phenotypes.

Identified genes conferring resistance against nonguideline recommended antibiotics were all consistent with reported phenotypes (Table 3). These included erythromycin resistance in two $S$. aureus samples (S20 and S51) where erm genes were reported, plus erythromycin and trimethoprim resistance in one $S$. aureus sample (S36) where erm and $d f r G$ genes were detected. Additionally, sul genes were detected in three cotrimoxazole resistant GNB-positive samples (S31, S37 and S59), possibly explaining the reported phenotype (Table 3).

The potential impact of CMg data was assessed against the guideline-recommended first-line empirical antibiotic treatment for VAP (piperacillin-tazobactam). CMg results would recommend meropenem rather than piperacillin-tazobactam in $11 / 20$ cases, based on speciation in 7 (35\%) and resistance-gene detection in 4 (20\%), and co-amoxiclav in 8 cases rather than piperacillin-tazobactam, based on speciation combined with the absence of $\beta$-lactamase genes (40\%). In $1 / 20$ (5\%) cases, CMg directed antibiotic choice was not consistent with culture (S34) where identification of an ESBL was not phenotypically reported by culture.

\section{Comparison of methods for diagnosis of IPA}

GM antigen detection tests were requested on BAL and serum samples from 16 (47\%) and 22 (65\%) patients, respectively, from the CMg group (Table 1). Nine patients had at least one mycology result consistent with IPA (Table 4). Four of five culture-positive patients met the original AspICU criteria, and all met the modified AspICU criteria that do not require predisposing host factors [34, 35]. Two-hour CMg sequence data identified A. fumigatus reads in all of the 3 culture-positive samples that were tested by CMg (S8 [77 reads], S28 [2649 reads] and S56 [79 reads]). Four persistently culturenegative patients had positive BAL-GM and met the modified AspICU criteria [4]; none of these had Aspergillus detected by CMg or qPCR (Table 4).

CMg detected $A$. fumigatus in a sample from a patient with $A$. fumigatus in other diagnostic samples (S55 [16 reads]) (Table 2). Probe-based qPCR was $100 \%$ concordant with $\mathrm{CMg}$ (Table 4). One sample from a patient (S18) growing A. fumigatus in additional tested samples was negative by culture, qPCR and metagenomic sequencing. CMg did not report any Aspergillus reads in the remaining culture-negative samples and was concordant with qPCR and culture (Additional file 1: Table S6).

Post-mortem histology from patient 563 with $A$. fumigatus identified by culture and CMg revealed a single 1 $\mathrm{cm} \times 1 \mathrm{~cm}$ patch of IPA and no A. fumigatus in other organs. There was extensive diffuse alveolar damage, and IPA was not reported to have contributed to death (Additional file 2: Figure S1).

\section{CMg detection of hospital transmission}

The higher than anticipated prevalence of Klebsiella spp. and $C$. striatum in respiratory specimens raised the possibility of patient-to-patient transmission (Fig. 2). This was investigated by comparing genomes from all patients reported with these organisms identified by both culture and $\mathrm{CMg}$, using reads obtained after $24 \mathrm{~h}$ of nanopore sequencing. Additional analysis combined with epidemiology linkage was then used to identify putative transmission networks amongst patients.

\section{Klebsiella pneumoniae}

Consensus sequence was generated using $K$. pneumoniae reads from 8 samples (8 patients). Different sequence types (ST) were determined in four samples (S11, S34, S59 and S63). No ST could be determined for three samples (S10, S31 and S61), and S49 was excluded from the analysis due to $3 \%$ genome coverage recovered (Additional file 1: Table S7A). Comparison of high-quality allele calls and pairwise comparison of bases from all 8 samples showed S31 was similar to S59 (ST307) with 55 SNP-based differences from 4,892,921 bases (99.999\% 
Table 3 Comparison of CMg-identified genotypic resistance with phenotypic culture results and the impact on guidelinerecommended beta-lactam antibiotic treatment

\begin{tabular}{|c|c|c|c|c|c|c|}
\hline Sample ID & $\begin{array}{l}\text { Bacteria reported by culture } \\
\text { and metagenomics }\end{array}$ & $\begin{array}{l}\text { Culture-reported } \\
\text { resistance }\end{array}$ & $\begin{array}{l}\text { CMg predicted } \\
\text { resistance }\end{array}$ & $\begin{array}{l}\text { Relevant genes } \\
\text { identified }\end{array}$ & $\begin{array}{l}\text { Genotype/phenotype } \\
\text { match? }\end{array}$ & $\begin{array}{l}\text { CMg-based treatment } \\
\text { recommendation }{ }^{\mathrm{a}}\end{array}$ \\
\hline S1 & K. aerogenes & No & - & - & Y & Meropenem \\
\hline S10 & K. pneumoniae & No & - & - & Y & Co-amoxiclav \\
\hline S11 & K. pneumoniae & No & - & - & Y & Co-amoxiclav \\
\hline S20 & S. aureus & Erythromycin & Erythromycin & erm & Y & Co-amoxiclav \\
\hline S21 & E. cloacae & No & No & - & Y & Meropenem \\
\hline S31 & K. pneumoniae & $\begin{array}{l}\text { ESBL } \\
\text { Co-trimoxazole }\end{array}$ & $\begin{array}{l}\text { ESBL } \\
\text { Co-trimoxazole }\end{array}$ & $\begin{array}{l}\text { bla }_{\mathrm{TEM},} \\
\text { bla }_{\mathrm{SHV}} \\
\text { bla }_{\mathrm{CTX}-\mathrm{M},} \\
\text { sul }\end{array}$ & $\begin{array}{l}Y \\
Y\end{array}$ & Meropenem \\
\hline S34 & K. pneumoniae & No & ESBL & $b l a_{\mathrm{TEM}}, b / a_{\mathrm{SHV}}$ & N & Meropenem ${ }^{b}$ \\
\hline S35 & A. baumannii & ESBL & - & & N & Meropenem \\
\hline S36 & S. aureus & $\begin{array}{l}\text { Erythromycin } \\
\text { Trimethoprim }\end{array}$ & $\begin{array}{l}\text { Erythromycin } \\
\text { Trimethoprim }\end{array}$ & $\begin{array}{l}\text { erm } \\
\text { dfrG }\end{array}$ & Y & Co-amoxiclav \\
\hline \multirow[t]{2}{*}{ S37 } & P. mirabilis & No & $\begin{array}{l}\text { Amoxicillin } \\
\text { Trimethoprim }\end{array}$ & $\begin{array}{l}b a_{\mathrm{OXA}} \\
d f r A\end{array}$ & $\begin{array}{l}N \\
N\end{array}$ & Meropenem \\
\hline & M. morganni & $\begin{array}{l}\text { Co-trimoxazole } \\
\text { Fosfomycin } \\
\text { Nitrofurantoin }\end{array}$ & $\begin{array}{l}\text { Co-trimoxazole } \\
- \\
-\end{array}$ & $d f r A$ & $\begin{array}{l}Y \\
N \\
N\end{array}$ & \\
\hline S39 & C. koseri & Amoxicillin & Amoxicillin & $b l a_{C K O}$ & Y & Co-amoxiclav \\
\hline S44 & S. marcescens & No & - & - & Y & Meropenem \\
\hline S49 & K. pneumoniae & ESBL & ESBL & $b l a_{\mathrm{TEM}}$ & Y & Meropenem \\
\hline \multirow[t]{2}{*}{ S51 } & S. aureus & Erythromycin & Erythromycin & erm & Y & Co-amoxiclav \\
\hline & C. koseri & Amoxicillin & Amoxicillin & $b l a_{C K O}$ & Y & \\
\hline S52 & K. aerogenes & Gentamicin & - & - & N & Meropenem \\
\hline S56 & P. mirabilis & $\begin{array}{l}\text { Amoxicillin } \\
\text { Co-trimoxazole }\end{array}$ & $\begin{array}{l}\text { Amoxicillin } \\
-\end{array}$ & $\begin{array}{l}b_{-} a_{\mathrm{TEM}} \\
-\end{array}$ & $\begin{array}{l}Y \\
N\end{array}$ & Co-amoxiclav \\
\hline S59 & K. pneumoniae & $\begin{array}{l}\text { ESBL } \\
\text { Co-trimoxazole }\end{array}$ & $\begin{array}{l}\text { ESBL } \\
\text { Co-trimoxazole }\end{array}$ & $\begin{array}{l}\text { bla } a_{\text {TEM, }} \\
\text { bla } \\
\text { sul }\end{array}$ & $\begin{array}{l}Y \\
Y\end{array}$ & Meropenem \\
\hline \multirow[t]{2}{*}{ S61 } & P. mirabilis & No & - & - & Y & Co-amoxiclav \\
\hline & K. pneumoniae & No & - & - & Y & \\
\hline S62 & K. aerogenes & ESBL & - & - & $\mathrm{N}$ & Meropenem \\
\hline S63 & K. pneumoniae & ESBL & ESBL & $b l a_{S H V}$ & Y & Meropenem \\
\hline
\end{tabular}

${ }^{a}$ Recommended antibiotics are those defined in the Guy's and St Thomas' Guideline for empiric and targeted first-line treatment for ITU-acquired ventilatorassociated pneumonia (VAP). Piperacillin-tazobactam is the first line empiric choice with recommendation to change therapy based on culture results and discussion with microbiology and infectious diseases. Meropenem is used for ESBL-Enterobacterales and E. cloacae, K. aerogenes (formally E. aerogenes), M. morganii and S. marcescens that have inducible $\beta$-lactam resistance. Co-amoxiclav is recommended for susceptible organisms

${ }^{b}$ Detection of ESBL by metagenomics for $K$. pneumoniae in this sample was not confirmed by culture

identical). This indicates a recent evolutionary history with differences likely due to nanopore sequencing errors. All other samples differed by tens of thousands of SNPs (Additional file 1: Table S7B).

Two additional patients (301 and 968) had a K. pneumoniae bloodstream infection (BSI) with identical broad resistance phenotype as CMg samples S31 and S59 (patient 1054 and 740, respectively). Pairwise comparison of SNP differences across all 4 genomes showed they were virtually identical with 5-55 SNP differences (Additional file 1: Table S7C). Together with the epidemiological analysis (Fig. 2A), this supported the transmission of this K. pneumoniae ST307 clone between 4 patients implicating an unsuspected outbreak.

\section{Klebsiella aerogenes}

Consensus sequence generated using $K$. aerogenes reads from S1, S52 and S62 identified 49,007 SNPs from $4,647,134$ bases in S1 and S52 (S62 was excluded due to low (1.5\%) genome coverage) making them only $98.94 \%$ identical. Additionally, S1 and S52 had 3 alleles in common (pryG(3), $\operatorname{rplB}(1), \operatorname{rpoB}(2))$ but differed in the allele 
Table 4 Mycological tests and clinical characteristics of patients with at least one result suggestive of invasive pulmonary Aspergillosis

\begin{tabular}{|c|c|c|c|c|c|c|c|c|c|c|}
\hline \multirow[t]{2}{*}{ Patient } & \multicolumn{4}{|c|}{ A. fumigatus detection in respiratory samples } & \multicolumn{2}{|c|}{$\begin{array}{l}\text { Galactomannan } \\
\text { (positive/tested) }\end{array}$} & \multicolumn{3}{|c|}{ AspICU - Putative Criteria [34] } & \multirow[t]{2}{*}{ ECMO } \\
\hline & $\begin{array}{l}\text { Sample } \\
\text { number }^{\mathrm{a}}\end{array}$ & $\mathrm{CMg}$ & qPCR (Cq) & $\begin{array}{l}\text { Culture } \\
\text { (Positive/Tested) }\end{array}$ & $\mathrm{BAL}>1.0$ & Serum $>0.5$ & Radiology & Clinical & Host & \\
\hline \multirow[t]{2}{*}{563} & $\mathrm{~S} 28$ & Positive & 31 & Positive & & & Yes & Yes & Yes - steroid & No \\
\hline & Other & ND & ND & $3 / 6$ & $0 / 1$ & $0 / 0$ & & & & \\
\hline \multirow[t]{2}{*}{613} & $\mathrm{~S} 18$ & Negative & $>40$ & Negative & & & Yes & Yes & No & No \\
\hline & Other & ND & ND & $2 / 2$ & $1 / 1$ & $0 / 0$ & & & & \\
\hline \multirow[t]{4}{*}{677} & 563 & Negative & $>40$ & Negative & & & Yes & Yes & Yes - steroid & No \\
\hline & S54 & Negative & $>40$ & Negative & & & & & & \\
\hline & S52 & Negative & $>40$ & Negative & & & & & & \\
\hline & Other & ND & ND & $0 / 8$ & $2 / 2$ & $0 / 5$ & & & & \\
\hline \multirow[t]{3}{*}{740} & S59 & Negative & $>40$ & Negative & & & Yes & Yes & Yes - leukaemia & No \\
\hline & $\mathrm{S} 30$ & Negative & $>40$ & Negative & & & & & & \\
\hline & Other & ND & ND & $0 / 16$ & $1 / 4$ & $1 / 2$ & & & & \\
\hline \multirow[t]{2}{*}{1033} & S8 & Positive & 33 & Positive & & & Yes & Yes & Yes - steroid & Yes \\
\hline & Other & ND & ND & $0 / 0$ & $1 / 1$ & $1 / 1$ & & & & \\
\hline \multirow[t]{2}{*}{1346} & S56 & Positive & 32 & Positive & & & Yes & Yes & Yes - steroid, anakinra & Yes \\
\hline & Other & ND & ND & $0 / 3$ & $1 / 1$ & $0 / 2$ & & & & \\
\hline \multirow[t]{2}{*}{1440} & S33 & Negative & $>40$ & Negative & & & Yes & Yes & Yes - steroid, anakinra & Yes \\
\hline & Other & ND & ND & $0 / 4$ & $1 / 2$ & $0 / 1$ & & & & \\
\hline \multirow[t]{3}{*}{1457} & S65 & Negative & $>40$ & Negative & & & Yes & Yes & Yes - steroid & Yes \\
\hline & $S 64$ & Negative & $>40$ & Negative & & & & & & \\
\hline & Other & ND & ND & $0 / 9$ & $2 / 2$ & $0 / 2$ & & & & \\
\hline \multirow[t]{2}{*}{1538} & S55 & Positive & 31 & Negative & & & Yes & Yes & Yes - lymphoma & No \\
\hline & Other & ND & ND & $4 / 5$ & $0 / 0$ & $1 / 1$ & & & & \\
\hline
\end{tabular}

$\mathrm{ND}=$ not done

${ }^{\mathrm{a}}$ Other sample represents samples from the nine patients, retrieved after an ITU episode but were outside the CMg period and were not processed with CMg

leuS (14 vs 29) indicating they had different sequencing types suggesting they were not part of an outbreak (remaining typing alleles were not fully called, and ST could not be determined).

\section{Corynebacterium striatum}

Analysis of consensus sequence using C. striatum reads from 5/6 samples (S45, S52, S54, S59 and S63-Additional file 1: Table S7D) from 4 patients showed 71,339 of 2,758,551 bases present in all consensus sequences (S62, patient 749, was excluded due to low (3.2\%) genome coverage). Reviewing all positions where there was a base in all samples, the maximum distance was 157 SNPs from 1,486,708 bases (99.99\% identity) implying they were part of an outbreak (Additional file 1: Table S7D). Epidemiological analysis of all 18 patients with $C$. striatum identified overlapping ward stays for $14 / 18$ patients across three ICUs, with genome sequence data (from CMg samples) implicating an extensive outbreak associated with patient movement between ICUs (Fig. 2B).

\section{Discussion}

COVID-19 ICUs are challenged with high rates of secondary infection and antimicrobial resistance, hence providing an impetus for the introduction of rapid (same day) results that can improve empiric treatment decisions. The current 'gold standard' culture-based diagnostics take $>48 \mathrm{~h}$ for pathogen and AMR identification [36]. CMg sequencing has the potential to provide sameday diagnosis ( $8 \mathrm{~h}$ turnaround) including pathogen identification $[9,12,37-42]$ and antimicrobial resistance prediction $[13,25,43]$. This data can be used to provide targeted antimicrobial therapy, before the second dose of broad-spectrum antibiotics is administered, and to characterise outbreaks $[13,44,45]$. In our study, we illustrate the potential use of rapid CMg sequencing in COVID19 ICU patients for improving antimicrobial stewardship and infection control investigations [46, 47]. A single respiratory $\mathrm{CMg}$ test provided bacterial and fungal identification and accurate AMR prediction within an 8-h laboratory workflow and data for molecular typing the 


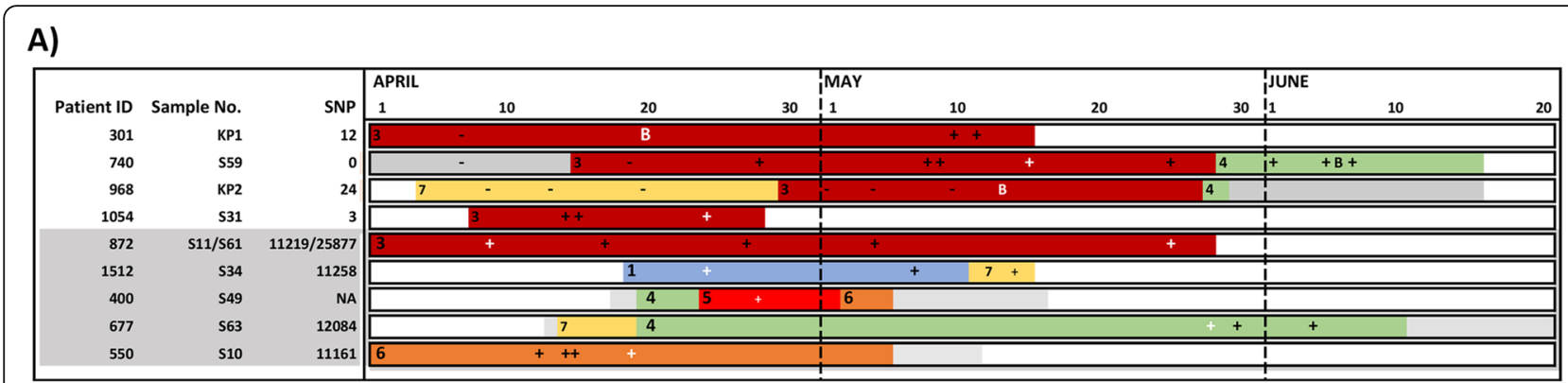

B)

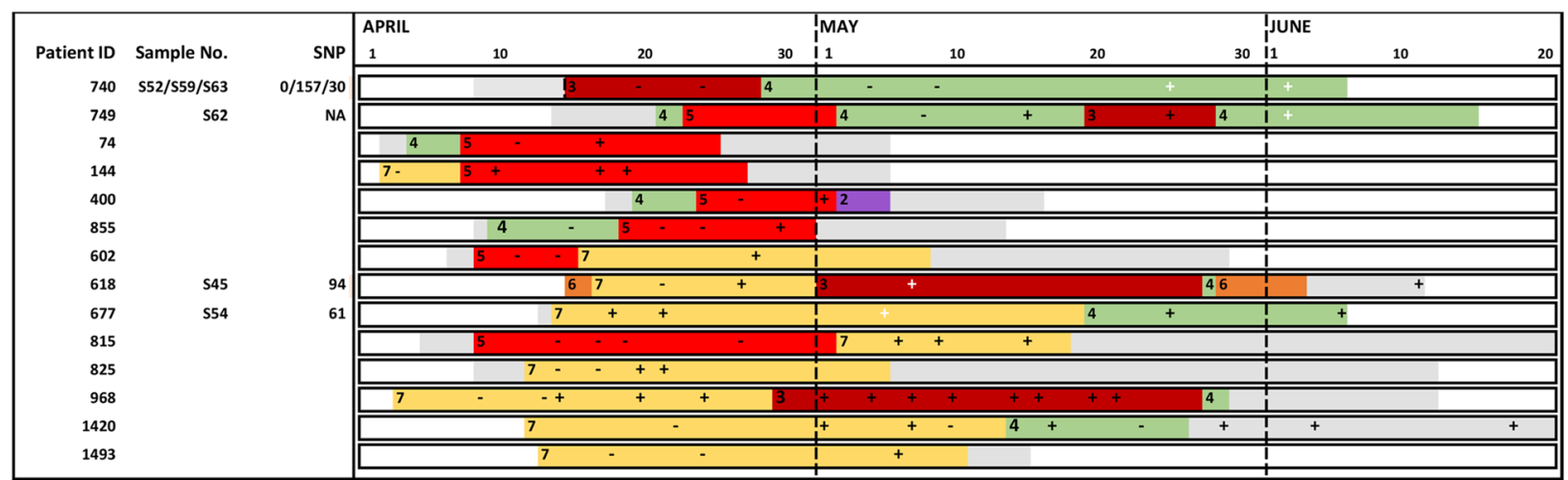

\begin{tabular}{|lll|}
\hline & ICU 1 & ICU 5 \\
$\square$ & ICU 2 & ICU 6 \\
$\square$ & ICU 3 & ICU 7 \\
$\square$ & ICU 4 \\
- & Negative respiratory sample by culture \\
+ & Positive respiratory sample by culture \\
क & Positive respiratory sample by culture and CMg \\
B & Positive blood culture \\
B & Positive blood culture, sequenced \\
\hline
\end{tabular}

Fig. 2 Identification of MDR K. pneumoniae and C. striatum outbreaks across the ICU network based on combined epidemiological and CMg analysis. Overlapping ward stays for patients involved in putative outbreaks of $\mathbf{A}$ ) MDR K. pneumoniae and B) C. striatum. Each row represents a unique patient. Patients are ordered by ward of first positive (ascending) and then by patient ID (ascending). The horizontal axis shows the ward stays from April 1 to June 20. Non-ITU wards are coloured in grey. ITU wards are labelled 1-10 represented by a unique colour. Periods outside the hospital are represented in white. MDR-K. pneumoniae or C. striatum positive and negative respiratory samples by culture are marked as ( + ) or $(-)$, respectively. Additionally, positive respiratory samples by CMg and culture are marked as "§". Positive blood cultures are marked as "B" and sequenced blood cultures are marked as "B". Patients with a CMg-aligned sequence have an S number (respiratory sample) or KP number (blood culture) adjacent to their identification number on the left of each bar. The number of SNPs for each CMg sample is also shown on the vertical axis. A) CMg was performed on MDR-K. pneumoniae in respiratory samples from patients 1054 and 301 and bloodstream infection isolates on patients 301 and 968 retrieved from the routine diagnostic laboratory (time point marked as "B"). Possible chain of transmission is from top to bottom. No sequenced patient could link 968 to 1517 or 618 to 740 and so were assumed to be due to cryptic transmission via other nonsequenced patients. B) CMg was performed on C. striatum in respiratory samples from patients 618, 677, 740 and 749. All other patients were linked by epidemiology only

following day (Fig. 1). Previous studies have provided examples of how metagenomics could be used for rapid diagnosis of infection and/or identifying transmission patterns, but here, these components are brought together with the background of expanded ICUs during the COVID-19 pandemic. Real-time provision of such data has the potential to fundamentally change the multi-disciplinary team approach to antimicrobial treatment, outbreak detection and AMR control on ICU.
CMg was $92 \%$ sensitive and $82 \%$ specific for bacterial and fungal detection, consistent with previous estimates $[9,16,48]$ using pre-defined thresholds. Thresholds and rules added for pathogen identification were to remove low-quality reads, low-level reagent/laboratory contamination, bioinformatic misclassification of reads and/or barcode cross-talk [9]. Less stringent thresholds for fungal identification were used as Aspergillus can be present in very low numbers in respiratory 
samples, and any growth (even a single colony) on fungal culture plates is reported as significant (scanty growth was reported for all Aspergillus culturepositive samples). More sensitive thresholds for fungal detection was also implemented by other $\mathrm{CMg}$ studies [12]. Using our CMg test, only two pathogens were missed in 2 culture-positive samples. Missed pathogens were within polymicrobial samples reported as scanty growth and were detected in the samples by $\mathrm{CMg}$, but below positivity thresholds. This indicates that the relative concentration of the missed pathogens was too low compared to the competing pathogens/bacteria in the samples to generate sufficient reads to pass thresholds. The clinical significance of minority pathogens in such samples could be questioned.

CMg also reported pathogens $(n=9)$ not identified by culture. Four out of the nine pathogens were reported in additional samples taken from these patients. From the remaining five pathogens, only two, S. aureus in S16 and S28, were likely to be false positive, probably due to $k$ mer misclassification of closely related non-pathogenic Staphylococci spp. (> 15,000 reads of S. epidermidis were reported in both samples). The remaining three organisms identified by metagenomics only, were likely to be true positives, as they are commonly found in respiratory samples, they were present at reasonable proportions of the reads and there was no evidence of cross-talk [9]. These pathogens could have been missed by culture because (a) the patients had received antibiotics prior to sampling, (b) they were present in samples with mixed infections and were not easily identified (Gram-negatives were reported in S37 and S44), or (c) the pathogen was present below the limit of detection of culture but not below the CMg LoD. Culture is a recognised imperfect gold standard, meaning the specificity of $\mathrm{CMg}$ is likely to have been underestimated.

We assessed how the impact of 2-h CMg AMR results could have modified the guideline-recommended empiric prescribing of piperacillin-tazobactam therapy, which is commonly used in the UK [49]. CMg accurately detected $\beta$-lactam resistance genes, consistent with phenotypic resistance to recommended antibiotics for the main respiratory pathogens, particularly Enterobacterales. Mismatch was only identified in 1 of 20 samples where an ESBL gene was identified in a sample containing phenotypically susceptible $K$. pneumoniae. $\mathrm{CMg}$ results would not inform piperacillin-tazobactam use in any case highlighting the shortcomings of making a single empiric antibiotic recommendation when such a broad range of bacteria and resistance phenotypes are possible. We could not compare carbapenem resistance with carriage of carbapenemase genes in Enterobacterales because neither were detected in this cohort. However, this is expected to be feasible using $\mathrm{CMg}$ sequencing as demonstrated previously by other studies $[9,50]$. Also, we did not attempt to determine phenotype from mutational resistances due to nanopore sequencing errors or from plasmid-borne resistances, as due to plasmid promiscuity would be challenging to determine the plasmid's host. However, both challenges could be overcome by using $\mathrm{CMg}$ data for genomic neighbour typing as previously demonstrated [13].

$\mathrm{CMg}$ also demonstrated potential for accurately diagnosing IPA. It detected all culture-positive samples and was $100 \%$ concordant with targeted qPCR, whereas half the patients with a positive GM result were not confirmed by the other three testing methodologies. Diagnosing secondary IPA is difficult with severe viral infections [4] and particularly COVID-19 patients, who commonly fulfil all radiological, clinical and host diagnostic criteria [51]. IPA in COVID-19 patients was uncommon in our study (about 2\%) as in other London centres [52]. The single small focus of the IPA in only one post-mortem reported here and elsewhere [53] suggests COVID-19-related IPA may not be as clinically significant as with influenza; however, this study was done during the first wave prior to evidence for benefit of steroid and toculizimab treatment that might increase frequency and severity of IPA. These encouraging preliminary $\mathrm{CMg}$ performance metrics need follow-up with larger sample cohorts to assess this technologies' potential as a diagnostic tool for IPA.

Finally, using 24-h CMg data, we identified the contribution of transmission towards the high prevalence of Klebsiella spp. and C. striatum observed here and elsewhere [54]. CMg identified an MDR-K. pneumoniae ST307 outbreak which is a particular concern given its resistance profile and extensive international spread [55]. $\mathrm{CMg}$ also identified an MDR-C. striatum outbreak potentially involving 14 patients. The clinical significance of detecting C. striatum in respiratory specimens is unclear although MDR-C. striatum outbreaks have been reported [56]. These findings highlight again the benefit of unbiased pathogen detection using $\mathrm{CMg}$ in revealing hidden outbreaks.

Further work is now required to consider $\mathrm{CMg}$ as a clinical service. For example, samples were batched in this study (6 per run) whereas delaying sequencing of specimens for batching reduces the benefit of having a rapid test. Singleplex sequencing using Flongle flow cells would be suitable for single runs, but processing samples at different times would have a significant impact on the microbiology laboratory workflow. Another issue is that only a small proportion of total COVID-19 ICU patients and samples were tested over 9 weeks due to limited staffing resources. For routine service, a scale up of 
resources would be required or decisions would need to be made on sample prioritisation.

The current method can only detect bacteria and fungi but not viruses. Modifying sample preparation could allow viral detection, enabling parallel diagnosis of respiratory infections independent of the causative agent. The negative control rule applied in this study was implemented to remove reagent or laboratory contaminants, such as E. coli, as previously done in other $\mathrm{CMg}$ studies $[57,58]$. However, removing contaminants in this way could result in the removal of true pathogens (such as E. coli) from respiratory samples which could negatively impact the sensitivity (not the case in this study). Alternatively, removing a certain proportion of contaminant reads from samples on the run could be done instead [59]. CMg-only dedicated laboratories with strict aseptic contamination-free techniques should be used for sample handling for $\mathrm{CMg}$. Also, an internal process control (IPC) could be used to tell the difference between method failures and true-negative samples. Further work is required to improve the bioinformatics analysis to minimise misclassification of closely related species. Both the development of the IPC and improved bioinformatics are underway.

\section{Conclusions}

This study demonstrates the potential for a single rapid $\mathrm{CMg}$ test to improve treatment of bacterial and fungal infections, improve antimicrobial stewardship and help identify nosocomial transmission and target infection control interventions. It demonstrates the full benefit of $\mathrm{CMg}$ for the whole multi-disciplinary team across laboratory scientists, intensivists, pharmacists and infection control experts, particularly in an ICU setting during this COVID-19 pandemic where the capacity challenges and disease severity can create unpredictable epidemiology and high levels of AMR [60]. The provision of such evidence for these hospital professional groups is required to get engagement on moving away from a predominantly culture-based approach and justify investment in $\mathrm{CMg}$. Further clinical evaluation of an ICU CMg service is our priority as this COVID-19 pandemic continues.

\footnotetext{
Abbreviations

AMR: Antimicrobial resistance; BAL: Bronchoalveolar lavage; BSI: Bloodstream infections; CMg: Clinical metagenomics; FAA : Fastidious anaerobic agar; GM: Galactomannan; GNB: Gram-negative bacteria; ICU: Intensive care unit; IPA: Invasive pulmonary aspergillosis; IPC: Internal positive control; LoD: Limit of detection; NDL: Non-direct bronchoalveloar lavage; PPE: Personal protective equipment; ST: Sequence type; VAP: Ventilator-associated pneumonia
}

\section{Supplementary Information}

The online version contains supplementary material available at https://doi. org/10.1186/s13073-021-00991-y.
Additional file 1: Supplementary Methods and Tables S1-S8. Table S1. List of pre-defined pathogen and reference source for each pathogen. Table S2. All non-pathogenic organisms identified in all respiratory samples processed with clinical metagenomics (above pre-defined thresholds). Table S3. Clinical characteristics and results of routine microbiological tests performed on intubated COVID-19 patients across 7 linked dedicated COVID-19 intensive care units on Guy's and St Thomas' hospital sites during the first wave of the COVID-19 pandemic. Table S4A. Sequencing metadata for all respiratory samples processed with clinical metagenomics. Table S4B. Negative controls run with each batch of samples sequenced. Table S5. Phenotypic resistance reported by culture and resistance genes reported by clinical metagenomics in all culture-positive samples after 2 hours of sequencing. Table S6. Microbiology, PCR and clinical metagenomics results for all samples processed in this study for the identification of Aspergillus fumigatus. Table S7A-D. Klebsiella pneumoniae and Corynebacterium striatum alignment for outbreak analysis. Table S8A-E. Performance reported after testing different parameters on training set for pathogen identification. The number of True Positive (TP), False Positive (FP), True Negative and False Negative (TN) samples as well as sensitivity, specificity along and calculated Youden's Index ((sensitivity+specificity)-1) are presented.

Additional file 2: Figs. S1-S3. Fig. S1A-B. Post mortem histological analysis of focal invasive pulmonary aspergillosis (IPA). Fig. S2. Receiver Operator Curve (ROC) curve analysis based on discordant testing $(\mathrm{CMg}+\mathrm{qPCR})$ performed for the training set. Fig. S3. WIMP alignment qscore plotted against the equivalent centrifuge score. Tested WIMP alignment $q$-scores are plotted on the $y$ axis against the equivalent centrifuge score on the $x$ axis.

\section{Acknowledgements}

We thank Dr. Vivek Sekhwat (speciality trainee, histopathology) and Ms. Lara Iredale (senior anatomical pathology technologist) for contributing to Additional file 2: Figure S1.

\section{Authors' contributions}

The study was designed by JDE, JOG and TC. Clinical data were collected by JDE, LBS, TGSM, CISM, CM, AG, UM and SG. Laboratory work and data analysis were performed by TC, AAM, LBS, AJP, JOG and JDE. Clinical samples were collected by AAM and were processed and analysed by TC, AAM and LBS. All authors read and approved the final manuscript.

\section{Funding}

This research was funded/supported by the National Institute for Health Research (NIHR) Biomedical Research Centre based at Guy's and St Thomas' National Health Service (NHS) Foundation Trust and King's College London, the programme of Infection and Immunity (RJ112/N027) JDE, LBS and TC. JOG was supported by the Biotechnology and Biological Sciences Research Council (BBSRC) Institute Strategic Programme Microbes in the Food Chain BB/R012504/1 and its constituent projects BBS/E/F/000PR10348, BBS/E/F/ 000PR10349, BBS/E/F/000PR10351 and BBS/E/F/000PR10352 and Innovate UK-China AMR grant TS/S00887X/1. AJP was supported by the Quadram Institute Bioscience BBSRC funded Core Capability Grant (project number BB/ CCG1860/1). CA is supported by a Guy's and St Thomas' Charity Fund grant TCF190910.

\section{Availability of data and materials}

Sequence data presented in this study are available on the European Nucleotide Archive (ENA) under project number PRJEB41184 (https://www. ebi.ac.uk/ena/browser/view/PRJEB41184?show=reads [61]).

\section{Declarations}

\section{Ethics approval and consent to participate}

Ethical approval for the use of surplus anonymized samples taken as part of routine care without written informed consent for the purpose of novel diagnostic development, including sequencing and data handling, was granted by the UK Health Research Authority/Research Ethics Committee (UK HRA and REC reference 20/SC/0310). All aspects of this study involving 
human participants and human samples were conducted in accordance with the 1964 Helsinki Declaration and its later amendments.

\section{Consent for publication}

Not applicable

\section{Competing interests}

JOG has received speaking honoraria, consultancy fees, in-kind contributions or research funding from Oxford Nanopore, Simcere, Becton-Dickinson and Heraeus Medical. The remaining authors declare that they have no competing interests.

\section{Author details}

${ }^{1}$ Centre for Clinical Infection and Diagnostics Research, Department of Infectious Diseases, School of Immunology and Microbial Sciences, Kings College London, London, UK. 'Infection Sciences, Viapath, St Thomas' Hospital, London, UK. 'Department of Infectious Diseases, Guy's and St Thomas' Hospital NHS Foundation Trust, London, UK. ${ }^{4}$ Quadram Institute Bioscience, Norwich Research Park, Norwich, UK. ${ }^{5}$ Critical Care Directorate, Guy's and St Thomas' Hospital NHS Foundation Trust, London, UK. ${ }^{6}$ Department of Cellular Pathology, Guy's and St Thomas' NHS Foundation Trust, London, UK

\section{Received: 16 April 2021 Accepted: 14 October 2021}

Published online: 17 November 2021

\section{References}

1. Edgeworth J. Oxford Textbook of Critical Care. Antibiotic resistance in the ICU: Oxford University Press; 2016

2. Torres A, Niederman MS, Chastre J, Ewig S, Fernandez-Vandellos P, Hanberger $\mathrm{H}$, et al. International ERS/ESICM/ESCMID/ALAT guidelines for the management of hospital-acquired pneumonia and ventilator-associated pneumonia. Eur Respir J. 2017;50(3):1700582.

3. Cookson WOCM, Cox MJ, Moffatt MF. New opportunities for managing acute and chronic lung infections. Nat Rev Microbiol. 2017:16:111.

4. Verweij PE, Gangneux J-P, Bassetti M, Brüggemann RJ, Cornely OA, Koehle $P$, et al. Diagnosing COVID-19-associated pulmonary aspergillosis. Lancet Microbe. 2020;1(2):e53-e5.

5. Ullmann AJ, Aguado JM, Arikan-Akdagli S, Denning DW, Groll AH, Lagrou K, et al. Diagnosis and management of Aspergillus diseases: executive summary of the 2017 ESCMID-ECMM-ERS guideline. Clin Microbiol Infect. 2018;24(Suppl 1):e1-e38.

6. Cox MJ, Loman N, Bogaert D, O'grady J. Co-infections: potentially lethal and unexplored in COVID-19. Lancet Microbe. 2020;1(1):e11.

7. Zhou F, Yu T, Du R, Fan G, Liu Y, Liu Z, et al. Clinical course and risk factors for mortality of adult inpatients with COVID-19 in Wuhan, China: a retrospective cohort study. Lancet (London, England). 2020;395(10229): 1054-62.

8. The Recovery Group. Dexamethasone in hospitalized patients with Covid19-preliminary report. N Engl J Med. 2020.

9. Charalampous T, Kay GL, Richardson H, Aydin A, Baldan R, Jeanes C, et al. Nanopore metagenomics enables rapid clinical diagnosis of bacterial lower respiratory infection. Nat Biotechnol. 2019;37(7):783-92.

10. Street TL, Barker L, Sanderson ND, Kavanagh J, Hoosdally S, Cole K, et al. Optimizing DNA extraction methods for nanopore sequencing of Neisseria gonorrhoeae; direct from urine samples. J Clin Microbiol. 2019; 10:01822-19. JCM.01822-19.

11. Thoendel MJ, Jeraldo PR, Greenwood-Quaintance KE, Yao JZ, Chia N, Hanssen $A D$, et al. Identification of prosthetic joint infection pathogens using a shotgun metagenomics approach. Clin Infect Dis. 2018;67(9):1333-8.

12. Gu W, Deng X, Lee M, Sucu YD, Arevalo S, Stryke D, et al. Rapid pathogen detection by metagenomic next-generation sequencing of infected body fluids. Nat Med. 2020;27:115-24.

13. Břinda K, Callendrello A, Ma KC, MacFadden DR, Charalampous T, Lee RS, et al. Rapid inference of antibiotic resistance and susceptibility by genomic neighbour typing. Nat Microbiol. 2020;5(3):455-64.

14. Services M. In: Unit S, editor. UK Standards for Microbiology Investigations. Evaluations, validations and verifications of diagnostic tests: Public Health of England; 2017. p. 1-45
15. Standards Unit MS, Public Health England. UK Standards for Microbiology Investigations. Investigation of bronchoalveolar lavage, sputum and associated specimens. 2018. Contract No.: 3.4 .

16. Langelier C, Kalantar KL, Moazed F, Wilson MR, Crawford ED, Deiss T, et al. Integrating host response and unbiased microbe detection for lower respiratory tract infection diagnosis in critically ill adults. Proc Natl Acad Sci. 2018;115(52):E12353.

17. Murphy CN, Fowler R, Balada-Llasat JM, Carroll A, Stone H, Akerele O, et al. Multicenter evaluation of the BioFire FilmArray Pneumonia/Pneumonia Plus Panel for detection and quantification of agents of lower respiratory tract infection. J Clin Microbiol. 2020;58(7):e00128-0.

18. Gadsby NJ, McHugh MP, Forbes C, MacKenzie L, Hamilton SKD, Griffith DM, et al. Comparison of Unyvero P55 Pneumonia Cartridge, in-house PCR and culture for the identification of respiratory pathogens and antibiotic resistance in bronchoalveolar lavage fluids in the critical care setting. Eur J Clin Microbiol Infect Dis. 2019;38(6):1171-8.

19. Fukumoto $H$, Sato $Y$, Hasegawa $H$, Saeki $H$, Katano $H$. Development of a new real-time PCR system for simultaneous detection of bacteria and fungi in pathological samples. Int J Clin Exp Pathol. 2015;8(11):15479-88.

20. Kim D, Song L, Breitwieser FP, Salzberg SL. Centrifuge: rapid and sensitive classification of metagenomic sequences. Genome Res. 2016;26(12):1721-9.

21. Pruitt KD, Tatusova T, Maglott DR. NCBI reference sequences (RefSeq): a curated non-redundant sequence database of genomes, transcripts and proteins. Nucleic Acids Res. 2007;35(Database issue):D61-D5.

22. Charalampous T, Medina-Alcolea A, Snell L, Williams GST, Batra R, Alder C, et al. What's In My Pot (WIMP) manual. Figshare. Available from: https:// figshare.com/articles/online_resource/Additional_file_3/16722829/1. 2021.

23. Andrew J, Page TLV, O'Grady J. Scagaire. GitHub. 2019.

24. TS. Abricate Github. Available from: https://github.com/tseemann/abricate

25. Ruppé E, Cherkaoui A, Lazarevic V, Emonet S, Schrenzel J. Establishing genotype-to-phenotype relationships in bacteria causing hospital-acquired pneumonia: a prelude to the application of clinical metagenomics. Antibiotics (Basel). 2017;6(4):30

26. Kos VN, Déraspe M, McLaughlin RE, Whiteaker JD, Roy PH, Alm RA, et al. The resistome of Pseudomonas aeruginosa in relationship to phenotypic susceptibility. Antimicrob Agents Chemother. 2015:59(1):427.

27. O'Leary NA, Wright MW, Brister JR, Ciufo S, Haddad D, McVeigh R, et al. Reference sequence (RefSeq) database at NCBl: current status, taxonomic expansion, and functional annotation. Nucleic Acids Res. 2016;44(D1):D733-45.

28. Li H. Minimap2: pairwise alignment for nucleotide sequences. Bioinformatics. 2018;34(18):3094-100.

29. Li H. A statistical framework for SNP calling, mutation discovery, association mapping and population genetical parameter estimation from sequencing data. Bioinformatics. 2011;27(21):2987-93.

30. Page AJ, Taylor B, Delaney AJ, Soares J, Seemann T, Keane JA, et al. SNPsites: rapid efficient extraction of SNPs from multi-FASTA alignments. Microbial Genomics. 2016;2(4).

31. Seemann T, mlst Github. https://github.com/tseemann/mlst.

32. Ferreira FA, Helmersen $K$, Visnovska $T$, Jørgensen SB, Aamot HV. Rapid nanopore-based DNA sequencing protocol of antibiotic-resistant bacteria for use in surveillance and outbreak investigation. Microbial Genomics. 2021;7(4).

33. Gu CH, Zhao C, Hofstaedter C, Tebas P, Glaser L, Baldassano R, et al. Investigating hospital Mycobacterium chelonae infection using whole genome sequencing and hybrid assembly. PLoS One. 2020;15(11): e0236533-e.

34. Blot SI, Taccone FS, Van den Abeele AM, Bulpa P, Meersseman W, Brusselaers $\mathrm{N}$, et al. A clinical algorithm to diagnose invasive pulmonary aspergillosis in critically ill patients. Am J Respir Crit Care Med. 2012;186(1): 56-64.

35. Schauwvlieghe AF, Rijnders BJ, Philips N, Verwijs R, Vanderbeke L, Van Tienen C, et al. Invasive aspergillosis in patients admitted to the intensive care unit with severe influenza: a retrospective cohort study. Lancet Respir Med. 2018:6(10):782-92.

36. Garcin F, Leone M, Antonini F, Charvet A, Albanèse J, Martin C. Nonadherence to guidelines: an avoidable cause of failure of empirical antimicrobial therapy in the presence of difficult-to-treat bacteria. Intensive Care Med. 2010;36(1):75-82.

37. Greninger AL, Naccache SN, Federman S, Yu G, Mbala P, Bres V, et al. Rapid metagenomic identification of viral pathogens in clinical samples by realtime nanopore sequencing analysis. Genome Med. 2015;7(1):99. 
38. Peddu V, Shean RC, Xie H, Shrestha L, Perchetti GA, Minot SS, et al. Metagenomic analysis reveals clinical SARS-CoV-2 infection and bacterial or viral superinfection and colonization. Clin Chem. 2020;66(7):966-72.

39. Langelier C, Zinter MS, Kalantar K, Yanik GA, Christenson S, O'Donovan B, et al. Metagenomic sequencing detects respiratory pathogens in hematopoietic cellular transplant patients. Am J Respir Crit Care Med. 2018; 197(4):524-8.

40. Wang J, Han Y, Feng J. Metagenomic next-generation sequencing for mixed pulmonary infection diagnosis. BMC Pulm Med. 2019;19(1):252.

41. Zinter MS, Dvorak CC, Mayday MY, Iwanaga K, Ly NP, McGarry ME, et al. Pulmonary metagenomic sequencing suggests missed infections in immunocompromised children. Clin Infect Dis. 2018;68(11):1847-55.

42. He B-C, Liu L-L, Chen B-L, Zhang F, Su X. The application of next-generation sequencing in diagnosing invasive pulmonary aspergillosis: three case reports. Am J Transl Res. 2019;11(4):2532-9.

43. Charalampous T, Kay GL, OeGrady J. Applying clinical metagenomics for the detection and characterisation of respiratory infections. The Lung Microbiome (ERS Monograph) Sheffield, European Respiratory. Society. 2019: 35-49.

44. Greninger AL, Zerr DM, Qin X, Adler AL, Sampoleo R, Kuypers JM, et al. Rapid metagenomic next-generation sequencing during an investigation of hospital-acquired human parainfluenza virus 3 infections. J Clin Microbiol. 2017:55(1):177-82.

45. Kafetzopoulou LE, Pullan ST, Lemey P, Suchard MA, Ehichioya DU, Pahlmann $M$, et al. Metagenomic sequencing at the epicenter of the Nigeria 2018 Lassa fever outbreak. Science. 2019;363(6422):74.

46. Edgeworth JD, Batra R, Wulff J, Harrison D. Reductions in methicillinresistant Staphylococcus aureus, Clostridium difficile infection and intensive care unit-acquired bloodstream infection across the United Kingdom following implementation of a national infection control campaign. Clin Infect Dis. 2020;70(12):2530-40

47. Edgeworth JD, Chis Ster I, Wyncoll D, Shankar-Hari M, McKenzie CA. Longterm adherence to a 5 day antibiotic course guideline for treatment of intensive care unit (ICU)-associated Gram-negative infections. J Antimicrob Chemother. 2014;69(6):1688-94.

48. Yang L, Haidar G, Zia H, Nettles R, Qin S, Wang X, et al. Metagenomic identification of severe pneumonia pathogens in mechanicallyventilated patients: a feasibility and clinical validity study. Respir Res. 2019;20(1):265.

49. Pilmis B, Jullien V, Tabah A, Zahar J-R, Brun-Buisson C. Piperacillintazobactam as alternative to carbapenems for ICU patients. Ann Intensive Care. 2017;7(1):113.

50. Sanderson ND, Swann J, Barker L, Kavanagh J, Hoosdally S, Crook D, et al. High precision Neisseria gonorrhoeae; variant and antimicrobial resistance calling from metagenomic nanopore sequencing. bioRxiv. 2020;20:1354-63. 2020.02.07.939322.

51. Beer KD, Jackson BR, Chiller T, Verweij PE, Van de Veerdonk FL, Wauters J. Does pulmonary Aspergillosis complicate coronavirus disease 2019? Crit Care Explor. 2020;2(9):e0211-e.

52. Heard KL, Hughes S, Mughal N, Moore LS. COVID-19 and fungal superinfection. Lancet Microbe. 2020;1(3):e107.

53. Carsana L, Sonzogni A, Nasr A, Rossi RS, Pellegrinelli A, Zerbi P, et al. Pulmonary post-mortem findings in a series of COVID-19 cases from northern Italy: a two-centre descriptive study. Lancet Infect Dis. 2020;20: 1134-40.

54. Dhesi Z, Enne VI, Brealey D, Livermore DM, High J, Russell C, et al. Organisms causing secondary pneumonias in COVID-19 patients at 5 UK ICUs as detected with the FilmArray test. medRxiv. 2020.

55. Strydom KA, Chen L, Kock MM, Stoltz AC, Peirano G, Nobrega DB, et al. Klebsiella pneumoniae ST307 with OXA-181: threat of a high-risk clone and promiscuous plasmid in a resource-constrained healthcare setting. J Antimicrob Chemother. 2020;75(4):896-902.

56. Verroken A, Bauraing C, Deplano A, Bogaerts P, Huang D, Wauters G, et al. Epidemiological investigation of a nosocomial outbreak of multidrugresistant Corynebacterium striatum at one Belgian university hospital. Clin Microbiol Infect. 2014;20(1):44-50

57. Miller S, Naccache SN, Samayoa E, Messacar K, Arevalo S, Federman S, et al. Laboratory validation of a clinical metagenomic sequencing assay for pathogen detection in cerebrospinal fluid. Genome Res. 2019;29(5):831-42.

58. Street TL, Sanderson ND, Atkins BL, Brent AJ, Cole K, Foster D, et al. Molecular diagnosis of orthopedic-device-related infection directly from sonication fluid by metagenomic sequencing. J Clin Microbiol. 2017;55(8): 2334-47.

59. Chiu CY, Miller SA. Clinical metagenomics. Na Rev Genet. 2019;20(6):341-55.

60. Vlek AL, Cooper BS, Kypraios T, Cox A, Edgeworth JD, Auquet OT. Clustering of antimicrobial resistance outbreaks across bacterial species in the intensive care unit. Clin Infect Dis. 2013;57(1):65-76.

61. Charalampous T, Medina-Alcolea A, Snell L, Williams GST, Batra R, Alder C, et al. Evaluating the potential for respiratory metagenomics to improve treatment of secondary infection and detection of nosocomial transmission on expanded COVID-19 intensive care units: BioProject PRJEB41184, European Nucleotide Archive; 2021. https://www.ebi.ac.uk/ena/browser/ view/PRJEB41184?show=reads

\section{Publisher's Note}

Springer Nature remains neutral with regard to jurisdictional claims in published maps and institutional affiliations.
Ready to submit your research? Choose BMC and benefit from:

- fast, convenient online submission

- thorough peer review by experienced researchers in your field

- rapid publication on acceptance

- support for research data, including large and complex data types

- gold Open Access which fosters wider collaboration and increased citations

- maximum visibility for your research: over $100 \mathrm{M}$ website views per year

At BMC, research is always in progress.

Learn more biomedcentral.com/submissions 